\title{
La religiosidad doméstica de las elites al servicio de la Monarquía en el siglo XVIII. Reflejos materiales de actitudes piadosas
}

\author{
Natalia GonZÁLEZ Heras \\ Universidad Autonoma de Madrid. \\ Instituto Universitario "La Corte en Europa" (IULCE) \\ natalia.gonzalez@uam.es
}

Fecha de recepción: 09/04/2015

Fecha de aceptación: 08/06/2015

\begin{abstract}
RESUMEN
Las prácticas religiosas hallaron dentro de la vivienda durante la Edad Moderna un marco excepcional para su desarrollo. En este artículo nos proponemos conocer los aspectos relativos a los ámbitos de la devoción y la piedad de las elites sociales madrileñas que ejercían un cargo al servicio de la Monarquía, a partir del análisis de los elementos materiales de carácter religioso que aparecen recogidos en las cuentas de capital, las cartas de dote y en los inventarios de bienes de sus miembros. La presencia de imágenes y objetos de carácter sagrado dentro de las distintas estancias que componían las viviendas, nos habrán de permitir calibrar el significado de lo religioso en la vida doméstica de aquellas familias, atendiendo a factores de carácter espiritual, siguiendo ciertas tendencias socio-culturales, por tradición o vinculación familiar, etc.
\end{abstract}

Palabras clave: Religiosidad, vivienda, elites, servidores de la Monarquía, espacios, cultura material.

\section{Domestic Religiosity of the Social Elites who Served the Monarchy During the Eighteenth Century. Material Images of Pious Attitudes}

\begin{abstract}
Religious practices found in the house during the Early Modern period an exceptional framework to their development. This article tries to find devotional and piety aspects in relation with the social elites in Madrid who served the Monarchy through the analysis of religious material objects which appeared into their capital accounts, dowry receipts and inventories. Images and objects with sacred value and their presence in the rooms which formed the house will allow us to consider the presence of Religion in those families domestic life, such answer to different requests: spiritual factors, socio-cultural trends, by familiar tradition or relationship, etc.
\end{abstract}

Key words: Religiosity, House, Elites, Monarchy Servants, Spaces, Material Culture. 


\section{INTRODUCCIÓN}

La presencia de objetos relacionados de una forma explícitamente directa con el ámbito de la devoción fue una constante dentro de la vivienda española durante la época moderna. En contraposición a la desaparición de las imágenes religiosas dentro de los distintos ámbitos en los territorios europeos en los que triunfó la Reforma protestante, en el contexto geográfico hispano -dentro del marco establecido por la Contrarreforma- se mantuvo un fuerte arraigo a la tradición iconográfica de carácter religioso, donde a las diversas representaciones de Cristo, la Virgen y los Santos se les dotaba de un valor sagrado ${ }^{1}$. Carmen Abad Zardoya reparó en la existencia de preceptos teóricos desarrollados dentro de la tratadística moral, donde se llevaba a cabo una serie de recomendaciones relativas a las devociones que debían practicarse dentro de la familia cristiana. Así, el padre franciscano Antonio Arbiol en su libro La familia regulada, cuya reimpresión fue reiterada a lo largo del siglo XVIII', dirigía hacia las devociones al misterio de la Santísima Trinidad, al de Jesucristo, al de la Cruz, al del Santísimo Sacramento del Altar, así como de santos y santas a quienes rendir fervor personal y que intercedieran entre el individuo y la divinidad ${ }^{3}$. El franciscano mantenía:

que en la casa feliz donde prevalece el amor ferviente de nuestro Redentor JesuCristo, descienden las bendiciones del Cielo, y no sólo abundan los bienes espirituales, sino que también se multiplican los temporales, para la mayor gloria, honra y servicio del mismo Señor, que dispone tengan sus verdaderos siervos lo que necesitan en este mundo transitorio ${ }^{4}$.

Asimismo, se ha de tener en cuenta la presencia de elementos de carácter variado relacionados con la liturgia y que se erigen en reflejo fehaciente de las prácticas rituales o ceremoniales que encontraban su espacio de desarrollo dentro de las casas particulares.

Desde estas páginas nos proponemos como objetivo principal llevar a cabo un estudio acerca de la presencia que tuvieron los elementos de carácter religioso dentro de las diferentes partes de las residencias madrileñas de los miembros de la elite social que ostentaban un cargo al servicio de la Monarquía. Para ello nos hemos basado en el análisis de un conjunto de escrituras notariales compuesto por 80 cartas de pago y

1 CARLOS, M. C. de, CIVIL, P., PEREDA, F. y VINCENT-CASSY, C: La imagen religiosa en la Monarquía hispánica. Usos y espacios, Madrid, Casa de Velázquez, 2008; CARO BAROJA, J.: Las formas complejas de la vida religiosa: Religión, sociedad y carácter en la España de los siglos XVI y XVII, Madrid, Akal, 1978; GONZÁLEZ SÁNCHEZ, C. A.: "Imagen de culto y espiritualidad. Funciones y normas de uso en la vida cotidiana (siglos XVI-XVIII)", en PEÑA DÍAZ, M. (ed.): La vida cotidiana en el mundo hispánico (siglos XVI-XVIII), Madrid, Abada, 2012 pp. 387-405

2 ARBIOL, A.: La familia regulada, primera edición en Zaragoza, Herederos de Manuel Román, 1715

3 Carmen Abad Zardoya en su conferencia "Uso, consumo y pautas de exhibición de la imagen religiosa en el espacio doméstico", dentro del marco del VIII Seminario La vida cotidiana en la España Moderna: Usos, tiempos y espacios de la vida cotidiana. Madrid, abril de 2014

4 ARBIOL, A.: La familia regulada, lib. III, cap. VIII. Edición consultada, Madrid, Gerónimo Ortega e hijos de Ibarra, 1789, p. 147 
recibo de dote, 20 cuentas de capital y 9 inventarios de bienes post-mortem otorgados por los precitados individuos, en escribanías madrileñas entre los años 1780 y $1803^{5}$.

Comenzaremos definiendo las que hemos establecido como principales vías o canales de introducción de dichos objetos como elementos compositores de las viviendas.

En primer lugar, su aparición podía responder a la voluntariedad por adquirirlos por parte de su propietario. En segundo lugar, haber sido transmitidos por medio de una herencia, tal y como aparece reflejado en las hijuelas de reparto de bienes entre herederos, cuando se producía el fallecimiento de alguno de los progenitores. Una segunda vía que, así mismo, se inserta dentro de la transmisión familiar del patrimonio a la que nos estamos refiriendo, consistió en escoger este tipo de bienes para que formaran parte de la dote que la novia iba a aportar a su matrimonio. Finalmente, un tercer canal es el que significó la donación o regalo de estos elementos, también como presentes de boda o como donaciones por vía testamentaria.

Dentro de la casa la funcionalidad de los objetos piadosos no estuvo limitada a lo que de partida se comprende como su razón de existencia innata, es decir, a cubrir las necesidades generadas en torno a su espiritualidad por parte de sus propietarios. Sino que, al mismo tiempo, adquirieron un importante valor como elementos de representación, a la vez en una doble vertiente. Por un lado, la riqueza material que caracterizaba a muchos de ellos, sirvió para dotarles de un significado simbólico, se constituyeron en reflejos de la riqueza de la persona que los poseía, alguien que iba a ser considerado de determinada categoría social y a quien se le iba a dotar de cierto grado de distinción. Por otro, contar con este tipo de bienes era indicativo, al mismo tiempo, de la condición religiosa y moral de buen católico del individuo a quien pertenecían, una actitud, la de manifestar la condición católica, firmemente arraigada en la sociedad española tras el Concilio de Trento.

De esta forma, las prácticas y actitudes relativas a la religiosidad, la piedad y la devoción, de las que eran indicativas el hecho de poseer determinados objetos, se insertan durante la segunda mitad del siglo XVIII dentro de la indefinición que caracterizó a este período respecto a los conceptos de público y privado. Es decir, una serie de actitudes que, por llevarse a cabo dentro del marco de la vivienda, que permitía en algunos de sus espacios el retiro de los fieles, no perdieron los matices de exhibición social que las caracterizaban cuando se practicaban en otros espacios, como durante las celebraciones en la iglesia o, en ciertas festividades, incluso en la calle.

\section{LOS ESPACIOS PARA LA DEVOCIÓN DENTRO DE LA VIVIENDA}

La ubicación de los objetos religiosos en una u otra estancia dentro de la casa iba a ser determinante a la hora de que aquellos fueran considerados en mayor o menor medida como elementos de decoración, de colección o relativos a las prácticas de

\footnotetext{
5 Puede consultarse un amplio desarrollo relativo al ámbito de las fuentes y la metodología utilizadas en el segundo capítulo de GONZÁLEZ HERAS, N.: Servir al rey y vivir en la corte: Propiedad, formas de residencia y cultura material en el Madrid borbónico, Tesis doctoral inédita. Universidad Complutense de Madrid, 2014.
} 
la devoción, propiamente dichas. En los siguientes apartados se penetrará en cada una de las estancias donde se ha podido constatar la existencia de piezas de carácter religioso, prestando atención al significado de dicha presencia según quién fuera su propietario o propietaria -manteniendo presente la variable del género, considerada fundamental dentro de los estudios relativos a la Historia de la cultura material ${ }^{6}$ - y el modo en que había accedido a formar parte de sus patrimonios. Lo que nos llevará a introducirnos en las experiencias de uso cotidiano generadas en torno a dichos bienes por parte de sus poseedores.

\section{El oratorio}

El oratorio constituía una estancia presente fundamentalmente en las residencias de la nobleza. Muchas son las casas principales datadas de los siglos XVI y XVII de las que tenemos noticia de la existencia de un oratorio. A ello se refería la condesa D'Aulnoy en su "cuestionado" libro de viaje: "Las iglesias de Madrid me han parecido muy hermosas y bien dispuestas, pero se ven poco frecuentadas por los grandes señores que oyen misa y rezan en las capillas particulares de sus casas. Sólo en ciertos días del año acuden a los templos, como por ejemplo, en Semana Santa"7.

Tal vez, se trataba de un testimonio que exageraba en exceso, como fue frecuente entre los relatos de viajeros ${ }^{8}$, las actitudes de las que se hacía eco; sin dejar por ello de servirnos como indicio para cuestionarnos respecto a la realidad que manifestaba.

Durante el siglo XVIII se desarrolló un intenso debate en torno al tema del uso de oratorios domésticos ${ }^{9}$. El hecho de que una vivienda disfrutara de un oratorio con-

6 EVANGELISTI, S.: "Cultura material y relaciones de género en la historiografía italiana de la Edad Moderna”, en PÉREZ-FUENTES HERNÁNDEZ, P. (ed.): Subjetividad, cultura material y género: Diálogos con la Historiografía italiana, Barcelona, Icaria, 2010, pp. 195-219; GONZÁLEZ HERAS, N.: "La esposa del funcionario: Cotas de poder femenino dentro de la residencia del hombre de Estado", en PÉREZ ÁLVAREZ, M. J., RUBIO PÉREZ, L. y MARTÍN GARCÍA, A. (eds.): Culturas políticas en el mundo hispánico, Madrid, FEHM., 2012, pp. 2105-2117; VICKERY, A.: "His and hers: Gender, consumption and household accounting in 18th century England" en ROPER, L. y HARRIS, R. (eds): The art of survival: Essays in honour of Olwen Hufton. Past \& Present (2006), pp. 12-38; "Fashioning difference in Georgian England: Furniture for him and for her", en FINDLEN, P. (ed.): Early Modern things: Objects and their histories, 1500-1800, Londres, Routledge, 2012. Sobre el tema concreto de la religiosidad femenina dentro de la vivienda: GARRIDO FLORES, A.: "La devoción en la casa: Córdoba en el Antiguo Régimen", Hispania Sacra, LXVI 134, juliodiciembre (2014), pp. 575-600

7 AULNOY, Condesa d': Viaje por España en 1679-1680, vol. I, Barcelona, Iberia, 1962, p. 186

8 FRANCO RUBIO, G. A. (coord.): Miradas propias y ajenas en un baile de espejos. Transferencias culturales entre España y Gran Bretaña en el siglo XVIII a través de los viajeros. Tiempos Modernos, n. 21/2 (2010)

9 Son diversas las fuentes que nos aproximan a esta controversia, ofreciendo perspectivas enfrentadas, entre otros textos (ordenados según su fecha de edición): GATTICO, J. B.: De oratoriis domesticis et de sus altares portatilis juxta veterem et recentem Ecclesiae disciplinam ecclesiasticorum seculariumque virorum singula jura et privilegia complectentem, Roma, apud Gregorium Roisechi, 1752; Anónimo: Disertación apologética a favor del privilegio que por costumbre introducida por la Bula de la Santa Cruzada goza la nación española en el uso de los oratorios domésticos. Leída en la Real Academia de Buenas letras de Sevilla en 25 de octubre de 1771, por el Doctor don Francisco de Paula Baquero, Sevilla, José Padrino; ERICE, J. J. de: Controversia moral sobre el uso de los oratorios domésticos, Pamplona, Antonio Castilla, 1788; SÁNCHEZ, A.: Carta crítica a una persona de carácter, de disciplina eclesiástica, sobre el uso de oratorios domésticos por el privilegio de la Bula de la Santa Cruzada, Madrid, Oficina de don Jerónimo Ortega y herederos de Ibarra, 
llevaba aparejado que al titular del domicilio se le hubiera concedido el privilegio de poder celebrar misa ${ }^{10}$ en el marco de su residencia particular, salvo en determinadas festividades del calendario litúrgico, como dejaba vislumbrar la condesa D'Aulnoy. Se trataba de evitar así un vacío en las iglesias por parte de sus feligreses de mayor estatus social en las fiestas de guardar. Sin embargo, según la normativa, no todas las celebraciones podían ser ejecutadas en los oratorios domésticos, ciertas funciones se mantenían reservadas a las iglesias, tales como bautizos, matrimonios, la ubicación de túmulos funerarios o columbarios ${ }^{11}$-salvo casos excepcionales-. Probablemente la realidad no se ajustara estrechamente a los preceptos y las prácticas llevadas a cabo dentro de los oratorios particulares pudieron superar a aquéllas que teóricamente estaban contempladas.

Para obtener la licencia que permitía disfrutar de un oratorio doméstico, estaba regulada la necesidad de exponer los motivos que llevaban a un individuo a presentar tal solicitud. Aquellos tendían a relacionarse con que el solicitante hubiera contribuido con algún tipo de servicio a la Iglesia y considerara que ésta debía reconocerle con tal privilegio; pero también con la avanzada edad y/o los problemas de salud que le impedían desplazarse a un templo para participar en los servicios religiosos. Por otra parte, se exponía así mismo la nobleza de la familia para la que se llevaba a cabo la demanda y se presentaban una serie de testigos de similar nobleza y calidad que pudieran certificar la veracidad de lo expuesto. El privilegio consistía en la concesión de una bula o breve papal -Bula de la Santa Cruzada-. Una vez obtenida ésta, debía ser el ordinario el que, tras comprobar en la propia vivienda, mediante la visita por parte de un sacerdote o por el propio fiscal del Arzobispado, la "decencia" del espacio destinado a oratorio, así en su fábrica como en su aderezo, otorgaba el visto bueno definitivo ${ }^{12}$. En el caso de Madrid, su pertenencia a la diócesis metropolitana de Toledo -la diócesis de Madrid no se creó hasta 1885, aún así como sufragánea de Toledo-, había derivado en el control directo respecto a los asuntos eclesiásticos sobre la Vicaría Eclesiástica y la Visita Eclesiástica. Esta última, dirigida por un visitador, que era

1792. Sobre oratorios domésticos en la América colonial: SÁNCHEZ REYES, G.: "Oratorios domésticos: piedad y oración privada", en GONZALBO AIZPURU, P. (coord.): El siglo XVIII: entre tradición y cambio, México, Fondo de Cultura Económica, 2005, pp. 531-552; ZAMORANO VAREA, P.: "Espacios domésticos de religiosidad. Los oratorios coloniales: Santiago siglo XVIII", en MILLAR CARVACHO, R. y RUSCONI, R. (coord.): Devozioni, pratiche e imaginario religios: espressioni del cattolicesimo tra 1400 e 1850: storici cileni e italiani a confronto, Roma, Viella, 2011, pp. 83-108

10 Para profundizar en la celebración de la eucaristía, BOSSY, J.: "The Mass as a social institution, 12001700", Past \& Present, n. 100 (Aug., 1983), pp. 29-61

11 VINUESA HERRERA, R. M.: "Oratorio y capillas privadas: la capilla del Beaterio de las MM. de la Orden Tercera de San Francisco de Sevilla”, en CAMPOS Y FERNÁNDEZ DE SEVILLA, F. J. (coord.): La clausura femenina en España, vol. II, El Escorial, Ediciones Escurialenses: Real Centro Universitario Escorial-María Cristina, 2004, p. 1069

12 Ibidem., pp. 1063-1078; VINUESA HERRERA, R. M.: "El oratorio de la casa natal del venerable don Miguel de Mañara, fundador Hospital de la Santa Caridad de Sevilla", en CAMPOS Y FERNÁNDEZ DE SEVILLA, F. J. (coord.): La Iglesia española y las instituciones de caridad, El Escorial, Ediciones Escurialenses: Real Centro Universitario Escorial-María Cristina, 2006, pp. 787-798 
nombrado por el arzobispo de Toledo, tenía entre sus competencias la supervisión de las parroquias, los edificios sagrados, altares, imágenes, mobiliario y vestimentas ${ }^{13}$.

La pieza del oratorio debía estar en una zona del plano alejada de los lugares en los que se desarrollaban actividades y tareas carentes de la gravedad que colmaba a la santa misa, "libre y separado de todas las ofiçinas y actos domésticos" ${ }^{14}$. Mantenerse con un aislamiento tal, que era preceptivo que en ningún caso pudiera servir de vía de paso para llegar hasta otra estancia, y que si existía una planta superior, sobre él no pudiera ubicarse ningún otro tipo de aposento, salvo otro oratorio.

La consulta de un total de 1.910 expedientes de licencias de obras en Madrid entre los años 1740 y 1803, nos ha permitido obtener 113 casos cuyos titulares solicitantes formaban parte de las elites al servicio de la Monarquía. Este conjunto nos ha facilitado el acceso a los planos de 162 viviendas, de las cuales sólo 2 reflejaban la existencia de un oratorio en el dibujo de su planta mediante un símbolo de la cruz.

\section{El oratorio en la vivienda de don Juan Miguel Fajardo Uztáriz}

Para el año 1747 contamos con el testimonio relativo a las casas que se disponía a construir sobre un sitio erial don Juan Miguel Fajardo Uztáriz, Secretario de Su Majestad y de Decretos en la Secretaría del Despacho Universal de Guerra, en la calle del Clavel con vuelta a la de San Miguel ${ }^{15}$.

Se trataba de una vivienda distribuida en dos alturas, bajo y principal. En el cuarto bajo, además de dos estructuras, compuestas por tres piezas cada una, con entradas por la fachada principal por la calle del Clavel, que comprendemos como dos tiendas con sus correspondientes aposentos; se hallaban las cocheras, las caballerizas y otras cuatro dependencias que desciframos destinadas a los servicios de la casa. Adosada a una de estas últimas se encontraba una escalera que conectaba con la zona de servicios que, así mismo, hemos distinguido dentro de la estructura compositiva del cuarto principal.

Sin embargo, en éste - el cuarto principal - las zonas de representación eran las que tenían reservada una mayor parte de la superficie de la planta. La escalera principal del inmueble daba acceso a un recibimiento que cumplía a su vez la función de distribuidor hacia las diferentes partes del cuarto. Una primera que se hallaba orientada hacia la fachada principal a la calle del Clavel, compuesta por varias estancias donde se perciben perfectamente una antesala, la sala, con una alcoba, y un gabinete. La segunda estructura se hallaba orientada hacia la fachada que miraba a la calle de San Miguel y guardaba una composición de aposentos en enfilade. Asimismo, desde el recibimiento se daba paso a una pieza alargada y de considerable anchura que se

13 FRANCO RUBIO, G. A.: "El estamento eclesiástico en Madrid durante el Antiguo Régimen", en ALVAR EZQUERRA, A. (coord.): Visión histórica de Madrid (Siglos XVI al XX), Madrid, Real Sociedad Económica Matritense de Amigos del País, 1991, pp. 62-63

14 VINUESA HERRERA, op. cit. (nota 11), pp. 1067

15 Archivo de Villa de Madrid (AVM.), Archivo de la Secretaría del Ayuntamiento (ASA.) 1-84-85. Figuras 1 y 2. Ver MARTÍNEZ MEDINA, A.: La casa nobiliaria española de los siglos XVII y XVIII: Historia, función, estructura y ornamentación, Tesis doctoral inédita, Universidad Complutense de Madrid, 1993, pp. $351-353$ 


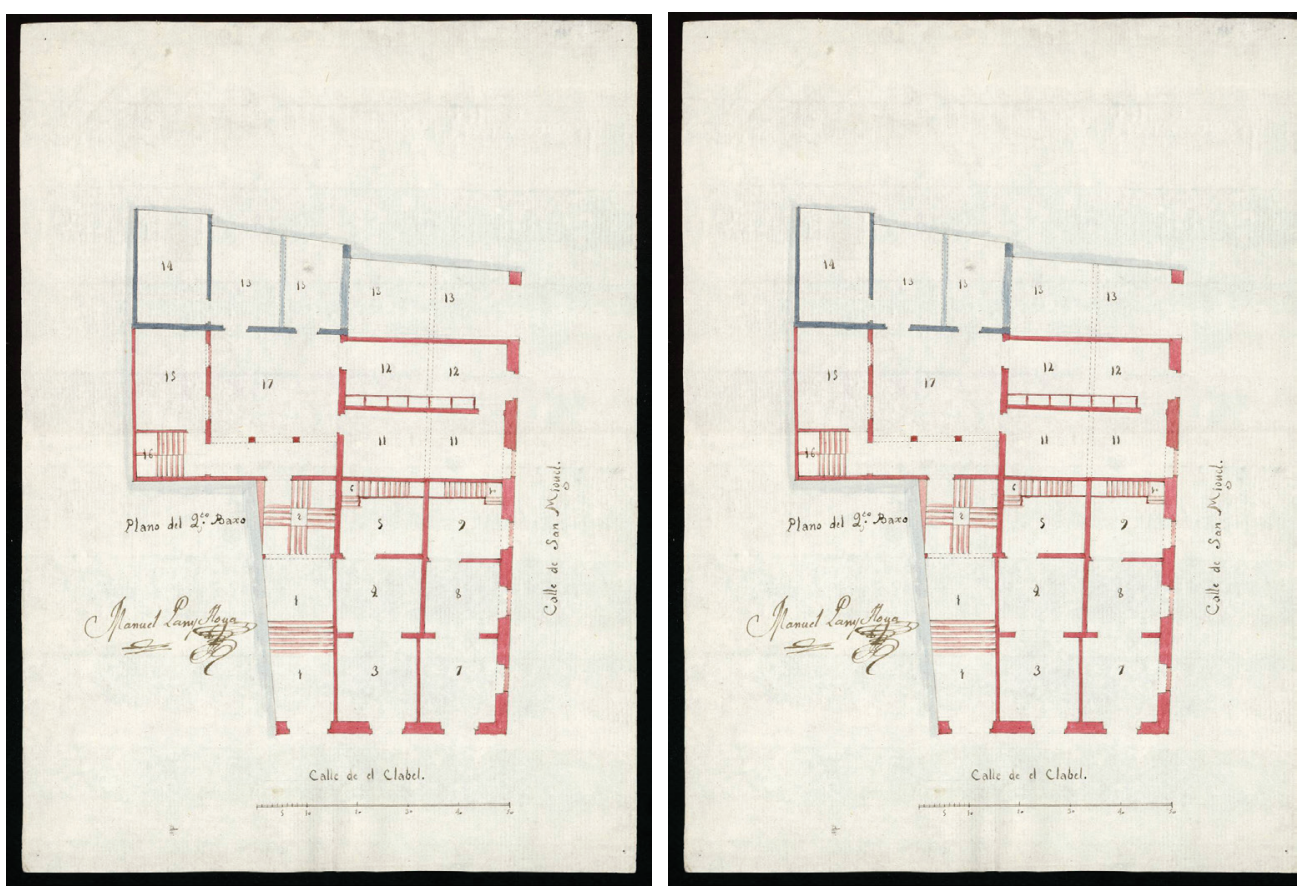

Fig. 1. Planta del cuarto bajo de la vivienda de don Juan Miguel Fajardo Uztáriz, 1747. AVM. ASA. 1-84-85.
Fig. 2. Planta del cuarto principal de la vivienda de don Juan Miguel Fajardo Uztáriz, 1747. AVM. ASA. 1-84-85.

iluminaba mediante dos ventanas abiertas hacia el patio. Por similitud a su posición dentro de la planta con respecto a otros planos analizados, la hemos identificado como el comedor/galería y desde éste se accedía a una tercera estructura de piezas entre las cuales se hallaba el oratorio.

El espacio sagrado estaba precedido por una estancia cuya ventana miraba de nuevo al patio y que se convertía en el único acceso a dos estancias que quedaban aisladas del resto de las de la casa en el ángulo noroeste del plano.

Un oratorio que, aún formando parte de una composición distributiva de piezas concebidas para mostrar la condición de su morador y, por lo tanto, a primera vista, abiertas a la penetración de todo aquél que llegara a la casa; guardaban, sin embargo, una graduación que las iba haciendo perder "publicidad", siguiendo el esquema que hemos utilizado para describirlas. Es decir, la parte más pública, la orientada hacia la fachada principal a la calle del Clavel; la menos, aquélla donde se encontraba el oratorio y que comprendía lo que debía ser un dormitorio bastante aislado del resto de dependencias que formaban el plano.

Su situación nos permite definir este oratorio como un espacio de carácter principal, aunque de acceso "reservado". Compréndase este término en el doble sentido de acceso "limitado" para el individuo al que se le había concedido la licencia de disfrute de oratorio particular - la cual tendía también a verse ampliada a los miembros de 
su familia y los posibles huéspedes de la casa -; al mismo tiempo que, siguiendo la definición del concepto "reservado" del Diccionario de la Real Academia Española en la primera de sus acepciones: "Cauteloso, reacio en manifestar su interior".

Tal y como ya se ha expresado, el edificio contaba con cuartos bajo y principal. Esto significaba que no hubo de plantearse la cuestión de cómo, atendiendo a la normativa, mantener el oratorio - ubicado en el principal - libre de cualquier otra pieza en altura sobre él que no tuviera su mismo carácter sagrado.

\section{El oratorio en la casa-palacio del II marqués de Grimaldo}

Existía también un oratorio en la casa-palacio cuya construcción ordenó don Bernardo de Grimaldo - II marqués de Grimaldo -, en el año 1763 en la calle Ancha de San Bernardo ${ }^{16}$. Heredero del título que le fue concedido a su padre, I marqués de Grimaldo, esta figura de trayectoria castrense y gentil-hombre de cámara del rey desde 1764, iba a disponer dentro de su residencia, de planeamiento propiamente palaciego, de un espacio específicamente destinado al culto religioso. Su situación dentro del entramado de piezas que componían la zona de representación de aquella planta noble, la dotaba de un carácter abierto de cara a quienes visitaban a los residentes de la casa. No obstante, su posición en la zona del testero del edificio, obligaba al recorrido de los múltiples aposentos de recepción que conformaban la parte frontal de la vivienda, que miraba a la fachada principal, y los de las dos alas laterales, con fachadas a las calles de la Manzana y de los Reyes, respectivamente, hasta alcanzar dicho "sancta sanctórum". Se reservaba así de facilitar un acceso directo a él en cualquier incursión en la vivienda y su orientación con ventana hacia el jardín le beneficiaba del sosiego y la quietud procedentes del espacio natural, las cuales iban a contribuir al mejor desarrollo de las prácticas de rezo y meditación para las que esta pieza estaba destinada.

Por otra parte, existía a su vez la posibilidad de conectar directamente con dicho lugar desde las zonas de comodidad o retiro de los habitantes del palacio. Éstas, dispuestas en torno al patio central de forma simétrica, atendiendo a los planteamientos de espacios de habitación diferenciados sexualmente dentro de la vivienda, por los que se abogaba desde las teorías moral y arquitectónica, le conferían, asimismo un valor trascendental, en toda la amplitud del término. Un espacio de superior importancia o gravedad con respecto al resto de las piezas que formaban la zona de respeto, del que se le dotaba por su carácter sagrado. A la vez, se permitía el uso directo de tal espacio por parte de la señora de la casa. Doña Irene de Navia, esposa del II marqués de Grimaldo desde el año 1750, e hija del marqués de Santa Cruz de Marcenado, tenía acceso desde sus piezas propias a aquel lugar sagrado, utilizado igualmente por parte de su marido. Lo que nos permite definirlo como un espacio neutro, en lo que a género se refiere, donde el hombre y la mujer podían desarrollar sus prácticas devocionales juntos o por separado ${ }^{17}$.

16 AVM. ASA. 1-45-37. TOVAR MARTÍN, V.: "Diseños para un palacio madrileño del siglo XVIII", Anales del Instituto de Estudios Madrileños, n. XXI (1984), pp. 53-67; El palacio del Ministerio de Justicia y sus obras de arte, Madrid, Ministerio de Justicia, 1986. Figuras 3 y 4

17 Según la teoría emanada desde la tratadística moral que regía el uso de capillas y oratorios particulares en el contexto italiano, el control directo de dicha pieza le correspondía al varón cabeza de familia. Agradezco 


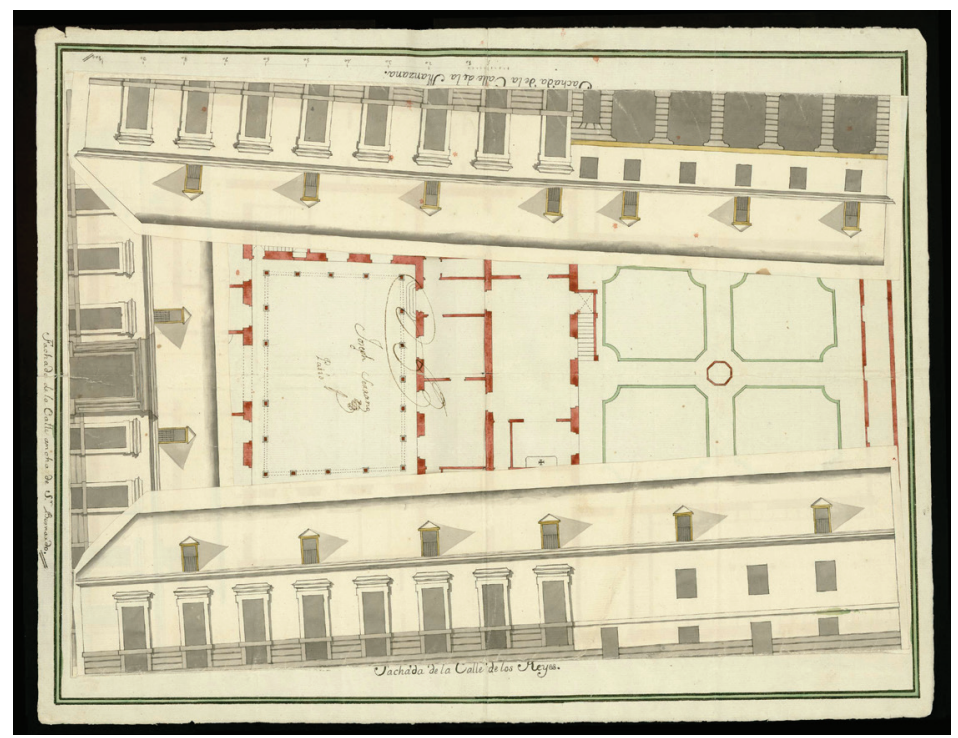

Fig. 3. Alzado de la casa-palacio del II marqués de Grimaldo, 1763. AVM. ASA. 1-45-37.

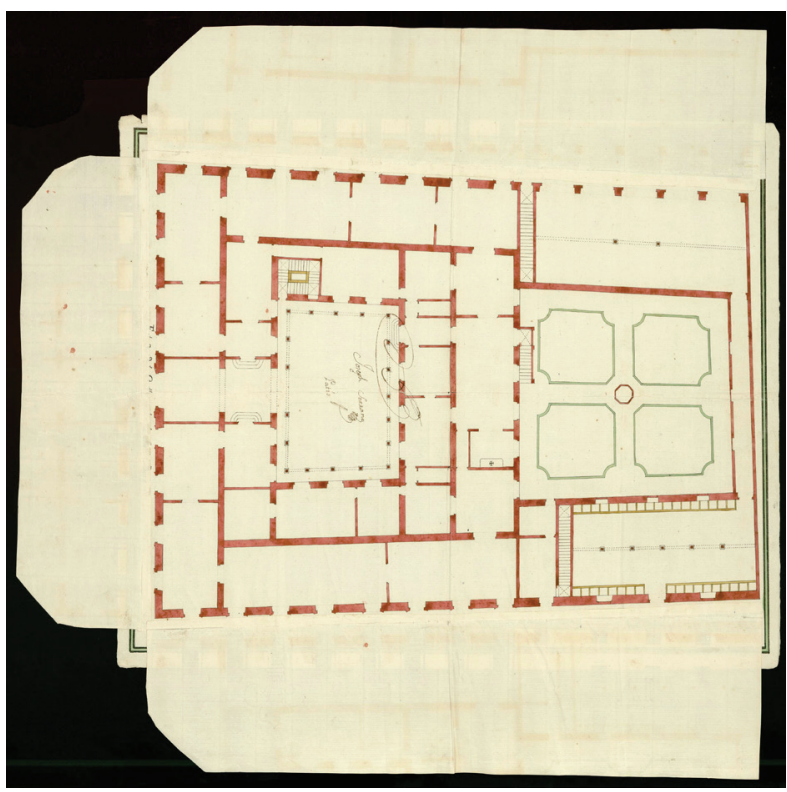

Fig. 4. Planta de la casa-palacio del II marqués de Grimaldo, 1763. AVM. ASA. 1-45-37.

dicha información a la Doctora Silvia Evangelisti, surgida a raíz del debate que se generó con la presentación del paper "Women, faith and devotional practices in late Eighteenth-century Spain and domestic material culture" en el marco del panel "Women's networks: Religion, culture and everyday life: Fifteenth to eighteenth century", European Social Science History Conference, Viena, abril 2014, por parte de quien al presente redacta estas líneas. 
El hecho de que en los dos casos de oratorios domésticos presentados, pese a la distancia tipológica existente entre la planta propiamente palaciega de la vivienda del marqués de Grimaldo y aquélla que no constituía un palacio como tal, aunque reflejaba la preeminencia socio-económica de su propietario, don Juan Miguel Fajardo Uztáriz, el oratorio fuera fácilmente accesible desde las que podemos entender como zonas de retiro de los moradores de la residencia, podía haber desatendido a los preceptos dados desde la normativa eclesiástica. Dependía así por completo de quienes podían disfrutar de tal dependencia de carácter sagrado no incurrir en oír misa desde la cama o en otra actitud -vestimenta- carente de la gravedad, la compostura y la circunspección que el rito requería.

Algunos miembros de la más alta aristocracia no se conformaron sólo con el privilegio de contar con su oratorio privado. Sino que, siguiendo ciertos precedentes establecidos por la monarquía, optaron por dotar a sus residencias de una comunicación directa con algún templo o monasterio ${ }^{18}$. Del mismo modo que el Alcázar de Madrid fuera comunicado con el monasterio de la Encarnación, la iglesia de San Gil y la parroquia de San Juan, el duque de Uceda pretendió llevar a cabo un proyecto arquitectónico, ya en el siglo XVII, para conectar su vivienda de la calle Mayor con el convento de monjas bernardas que fundó junto a ella. Del siglo XVII datan así mismo varias ejecuciones de obras de este tipo, analizadas dentro el contexto urbanístico del Madrid moderno por Virginia Tovar. Entre otras, las construcciones que se aprobaron por parte del Ayuntamiento en el año 1624 para unir las casas de la marquesa del Carpio con la iglesia parroquial de San Justo y Pastor y la casa principal de la marquesa del Valle con el convento de Clérigos Menores del Espíritu Santo; en 1625 la unión de las casas del marqués de la Laguna con la iglesia de Santiago, tomando como modelo el pasadizo situado en la calle del Prado y que unía el convento de Santa Catalina de Sena con el palacio del duque de Lerma. También, la arquitectura de paso que fuera construida ya durante la segunda mitad del siglo XVII -1667- a petición de la marquesa de Valle de Serrato y la condesa de Salvatierra para unir las casas que poseían en la Plazuela de la Villa con la parroquia de San Salvador. Se observa así la intencionalidad de aquella nobleza servidora de la monarquía de equipararse con esta última, mediante el goce de determinados usos de carácter privativo, muy alejados del alcance del común.

En el siglo XVIII se mantuvo la misma dinámica, y a los casos precitados se sumaron el pasadizo que se construyó con licencia obtenida en 1715 entre las casas principales del duque de Santisteban y la iglesia de San Pedro, muy próximo al que databa del siglo XVI y que unía las casas principales de los duques del Infantado en la Costanilla de San Andrés con la tribuna de la vecina iglesia de San Andrés; y el que se construyera para unir las casas del marqués de Almonacid con el convento de los Afligidos $-1717-{ }^{19}$.

18 TOVAR MARTÍN, V.: "El pasadizo, forma arquitectónica encubierta en el Madrid de los siglos XVII y XVIII", Villa de Madrid, n. XXIV (1986), pp. 31-42 y MORA LORENZO, C. de: "El pasadizo en el Madrid de los Austrias (siglo XVII). Pervivencia de elementos arquitectónicos encubiertos de tradición medieval", Madrid revista de Arte, Geografia e Historia, n. 6 (2004), pp. 259-287

19 TOVAR MARTÍN, op. cit. (nota 18), pp. 31-42 
Resulta igualmente relevante en el análisis de las conexiones existentes entre las viviendas de particulares y los espacios para el culto, añadir que también hubo oratorios de origen doméstico que acabaron convirtiéndose en templos propiamente dichos. Una muestra de ello fue San José, iglesia fundada en 1747, como anexo de la parroquia de San Ginés, en lo que hasta entonces habían sido unas casas con oratorio privado del duque de Frías, don Bernardino Fernández de Velasco -quien las donó-, situadas en el barrio del Barquillo. La figura del noble se mantendría directamente vinculada al templo mediante su compromiso de costear ciertos gastos relacionados con el culto - los servidores necesarios y la cera y el aceite que iban a alumbrar al Santísimo- ${ }^{20}$.

Se debe incidir en el valor como representación de elevado estatus social que existía tras este tipo de materializaciones vinculadas al terreno de lo religioso. De forma que, los miembros de aquellos grupos en vías de ascenso dentro de la pirámide poblacional que constituían los servidores del Estado, simularon en sus prácticas a la nobleza tradicional que había copado su vértice. Tómense los casos analizados relativos al disfrute de un oratorio doméstico. Pero también en la fundación de capillas dentro de los templos, así, el I marqués de Santiago, dentro de su estrepitosa carrera por dotar de contenido a su nueva nobleza, fundó la capilla de Belén en la iglesia del Salvador, sita en la Plazuela de la Villa. Aquélla fue construida por Gabriel Valenciano entre 1713 y 1716 y constaba de un retablo churrigueresco, además de pinturas murales de Palomino ${ }^{21}$. Su elección no debió ser en absoluto arbitraria, puesto que dicho templo constituía un escenario incomparable en el que exhibir su condición, en el que solían celebrarse las juntas habituales del concejo madrileño.

Si pasamos a considerar el mobiliario vinculado a las prácticas religiosas que componía los oratorios domésticos, nos detendremos, en primer lugar, en el mueble contenedor de los elementos necesarios para la liturgia. La tipología sería equiparable con la del ejemplar que aparecía entre los bienes inventariados tras el fallecimiento del marqués de Portago en 1754. Don José Gómez de Terán, ministro del Tribunal de la Contaduría Mayor y consejero del Consejo Real de Hacienda poseía en sus casas principales de la calle Príncipe: "Un armario cubierto de diferentes maderas por dentro y fuera que ha servido de oratorio de tres baras menos cuarta de alto y dos y cuarta de ancho con su cerradura y falleba en mil doscientos" 22 . Acompañando a éste debieron situarse también dos tipologías muebles cuya presencia se estima infrecuente dentro de las viviendas analizadas - sólo hemos hallado referencias a las mismas en la mencionada escritura -. Se trataba del confesionario y del humilladero.

El confesionario era el lugar destinado para oír las confesiones sacramentales y se componía habitualmente de una silla que a los lados tenía celosías o unas rejillas por donde el confesor escuchaba al penitente. No había de ser en exceso sofisticado el realizado en pino y tasado en 50 reales de vellón propiedad del marqués ${ }^{23}$. Sin embargo, su mera presencia era indicativa ya de la importancia que se le concedía dentro de

20 FRANCO RUBIO, G. A.: “La organización eclesiástica del Madrid de la Ilustración”, Anales del Instituto de Estudios Madrileños, n. XXIII (1986), pp. 271-288; y op. cit. (nota 13), p. 69

21 Ver FRANCO RUBIO, op. cit. (nota 13), p. 66

22 Archivo Histórico de Protocolos de Madrid (AHPM.), Protocolo (Prot.) 16471

23 AHPM. Prot. 16471 
aquella residencia a la práctica religiosa. El mismo significado podemos otorgarle a la existencia de un humilladero o reclinatorio, en el que postrarse para orar. Éste constituía una pieza de valor material superior a la anterior; su vara de altura, cobertura de nogal y perfiles en marfil, con cuatro navetas y su almohada de damasco encarnado dieron lugar a que fuera tasado en 360 reales de vellón ${ }^{24}$. No obstante, su uso en el espacio doméstico es un hecho constatado, incluso en esferas inferiores de la sociedad, teniendo en cuenta la posibilidad de poder alquilar esta tipología mueble, con unas características, materialmente hablando, muy básicas, en el negocio de alquiler de mobiliario que poseía don Roberto Fourdiner en la capital: "Un reclinatorio de pino dado de color amarillo con su banquillo en 15 reales de vellón" 25 .

Se considera interesante llevar a cabo una reflexión en torno a los conceptos utilizados para denominar esta última pieza, ilustrativos de la forma de comprender la religión por parte de la sociedad española del siglo XVIII. Mientras en España los términos al uso eran "humilladero" y "reclinatorio", ambos cargados de connotaciones relativas a la sumisión del fiel hacia la divinidad; en Francia, para el mismo período, el concepto utilizado era "prie-Dieu", es decir, el lugar específico para rezar a Dios. De forma que se perciben dos formas distintas de relación entre el hombre y el Ser supremo en estos dos territorios vecinos y de una misma confesión religiosa.

La ubicación de estos tres elementos muebles dentro de una misma estancia de las casas principales del consejero de Hacienda resulta indicativa de la existencia de un espacio específico destinado a las prácticas religiosas de la familia.

La cerradura con llave de la puerta del mueble-oratorio del marqués de Portago, así como la que sellaba la pieza oratorio de la residencia que en la plazuela de Puerta Cerrada se disponía a ocupar el matrimonio formado por don Juan de la Cruz Belbis de Moncada y Pizarro, conde de Villamonte, y doña María de la Encarnación Toledo y Gonzaga, hija de los marqueses de Villafranca ${ }^{26}$, debían responder al interés por mantener a buen recaudo los objetos de valor que se encontraban en los mismos.

En el caso de los condes de Villamonte, un cáliz con pie, una copa patena dorada por dentro y una cucharita, fueron tasados en 213 reales y cuartillos de plata. Estaban dotados de un importante valor económico, resultado de los materiales sobre los que estaban fabricados; pero también de un valor simbólico, el cual portaban los elementos de carácter sagrado y/o utilizados en la liturgia y, finalmente, en algún caso, podían poseer incluso valor como legado familiar. Tal y como quedara reflejado para el cáliz al que en su testamento se refiriera la escritora y traductora madrileña Inés Joyes -1731-1808-, que se había ido transmitiendo dentro de su familia, generación tras generación ${ }^{27}$.

La ubicación de los objetos precedentes en un cajón de la sacristía, lugar específico para custodiar los ornamentos de oratorio pertenecientes al culto, a su vez, dentro de una pieza oratorio que podía ser cerrada con llave, evitaba, en definitiva, una posible profanación de los objetos y del espacio religioso.

\footnotetext{
24 Ibidem.

25 AHPM. Prot. 21878/405 r.

26 AHPM. Prot. 18185, f. 662 r.-710 v.

27 BOLUFER PERUGA, M.: La vida y la escritura en el siglo XVIII. Inés Joyes: Apología de las mujeres Valencia, Universitat de Valencia, 2008
} 
La imagen sagrada que debía centrar el culto en aquel oratorio doméstico de las casas principales de los condes de Villamonte en Puerta Cerrada era una efigie de Cristo en la Cruz. Realizado el cuerpo en marfil y el árbol de ébano, todo el conjunto, sustentado sobre una peana y pilares de la misma madera, había sido tasado en 1.500 reales de vellón. En éste se aprecia un triple valor, similar al reflejado para los elementos anteriores. Por un lado el piadoso; una imagen, en esta ocasión de bulto, destinada a ser objeto de devoción. Por otro, el inherente a la obra de arte, una pieza de decoración, representativa incluso de una posible faceta como coleccionistas de sus propietarios. Y, finalmente, el valor simbólico-social que se transmitía a través de la riqueza de los materiales en los que estaba realizada la escultura o su autoría por parte de determinado artista, los que encumbraban a dichos propietarios a determinados niveles de distinción respecto a quienes no contaban con una obra de tales características.

A partir del análisis de este conjunto es imperceptible rasgo alguno que pudiera dotar a aquel espacio y a su composición de unas connotaciones que los relacionaran directamente con las devociones del señor o la señora de la casa. Según la documentación nos informa, la nueva residencia del matrimonio formado por los condes de Villamonte se compuso a costa del adelanto de las legítimas paterna y materna de don Juan Belbis de Moncada. Por lo que bien se podrían incluso intuir a partir de dichos elementos materiales las devociones particulares de los padres del señor, los marqueses de Bélgida. De forma que, el oratorio se definía como un espacio mixto, abierto a las prácticas devocionales por parte de ambos sexos y, por extensión, de los diferentes miembros de la familia.

Otros elementos que aparecían formando parte de los oratorios eran las vinajeras. Se trataba de dos pequeños jarros hechos para contener y servir el vino y el agua durante la misa. Su elaboración en plata o plata sobredorada y el posible adorno o labrado del metal precioso las convertían en piezas de importante valor económico, a la vez que estético. De su aparición entre los bienes dotales, frente a su inexistencia entre los que componían las cuentas de capital masculino ${ }^{28}$, podemos interpretar que se convertían, tal vez, en indicativas de una de las atribuciones que, dentro de la nueva familia que se formaba a partir del lazo matrimonial, se le iba a asignar a la mujer. Tenía que ver con su faceta de católica devota. Pero, asimismo, entrañaba un especial significado cuando se trataba de piezas que habían formado parte de la familia durante generaciones y que se estaban transmitiendo por vía femenina a la nueva familia que resultaba del matrimonio, erigiéndose así la mujer en continuadora de la estirpe, según los preceptos de la tratadística moral relativa a la familia, que en poco o nada se alejaba de aquélla de los siglos precedentes ${ }^{29}$.

\footnotetext{
28 No obstante, no debemos perder de vista que dentro de la documentación sobre la que nos encontramos realizando este estudio las escrituras de dote cuadriplican al número de escrituras de cuenta de capital masculino. Sin embargo, cabe remarcarse que la aparición de elementos diferentes a los textiles, destinados a vestir la casa y los correspondientes a la indumentaria de la propia mujer, era muy infrecuentes dentro de los conjuntos que formaban parte de sus dotes para las primeras nupcias en el Madrid de la segunda mitad del siglo XVIII. Por lo que la presencia de estos objetos es ya reseñable en sí misma.

29 Entre otros tratados, para el siglo XVI: LEÓN, Fray Luis de: La perfecta casada, ARBIOL, op. cit. (nota 2), la primera edición de 1715 fue reiteradamente reeditada a lo largo del siglo XVIII.
} 
Observemos el caso de la dote aportada a su matrimonio en mayo de 1803 por doña María Josefa Surbille Abad Wautres y Cifuentes con don Tomás de Estrada y Lancero, guardia de corps de la Compañía Flamenca. La hija del difunto don Luis Surbille, quien fuera archivero general de la Secretaría del Despacho Universal de Indias, llevaba entre otros elementos: "Dos vinagreras de plata caladas, su peso veinte y dos onzas, cuatrocientos y cuarenta reales. Hechura a ciento y sesenta reales cada una, trescientos y veinte" 30 . A su valor económico -760 reales de vellón- se sumaba el valor familiar. Los bienes que componían el cuerpo de aquella dote formaban parte de la herencia paterna, a los que había que sumar otros, propios de su madre, doña Eulogia Abad y Cifuentes, y los heredados de un primer matrimonio de la contrayente con don Manuel Uriarte y Leoz, que ocupara cargos en torno a la década de 1780 de contador y secretario del Duque de Osuna ${ }^{31}$.

Otros elementos de carácter religioso que caben ser destacados dada su reiterada aparición dentro de las listas de bienes domésticos y personales inventariados son las pilas para agua bendita. Aparecen en un 33\% de los inventarios de bienes postmortem analizados, en un $16,25 \%$ de las cartas de pago y recibo de dote y en un $15 \%$ de las cuentas de capital.

Debemos relacionarlas con su función como recipientes contenedores de agua, cuyo significado simbólico tenía que ver con la purificación o limpieza espiritual. Pese a que en la sociedad que nos hallamos analizando el uso del agua en las prácticas relativas a la higiene corporal había perdido casi totalmente su importancia, con respecto a la tradición de civilizaciones como la romana o la musulmana; viéndose reducida su utilización para el lavado de la cara y las manos, fundamentalmente, y siendo sustituida en la higiene del resto del cuerpo por el cambio o "muda" de la ropa interior blanca, realizada en tejidos como el algodón o el lienzo, el agua en la religión cristiana mantenía el significado de sustancia que limpiaba, que purificaba y era utilizada con este fin en rituales como el llevado a cabo durante el sacramento del bautismo o en los rituales de lavatorios. Además, según fray Antonio Arbiol: "El uso sagrado del agua bendita, es también muy conveniente en todas las casas, y para todas la personas, porque es un eficaz defensivo contra la vigilancia y conato del demonio..." 32 . Dichas pilas eran sin duda objetos de carácter suntuario de los que su elaboración en plata y sus consecutivos precios daban fe. Mostraban así la condición distinguida de sus propietarios, pero, a su vez, su posesión por parte de las novias podía tener que ver con la pureza que cabía esperarse de la futura esposa, en relación al beneficio purificante que se asociaba al agua bendita que dichas pilas estaban destinadas a contener.

Unas pilas que, al mismo tiempo, podían mostrarse en reflejo del origen familiar o social de quien las poseía, como ocurriera con la que formara parte de la dote de doña Manuela María Martínez de Laguna. Ésta, perteneciente al Gremio del lienzo y con tienda en la calle de las Postas por fallecimiento de su primer marido, don Tomás

30 AHPM. Prot. 21756, f. 409 r.

31 FICHOZ: 041257. En la base de datos aparece mencionado como Manuel Uriarte Hoz, mientras en el documento notarial lo hace como Manuel Uriarte y Leoz. No obstante, no dudamos de que la identidad corresponde a la misma persona.

32 ARBIOL, op. cit (nota 4)., lib. III, cap. VIII, p. 150 
de Uriarte, aportó a su segundo matrimonio, con don Francisco Bovadilla Alcocer, subteniente de las milicias de la ciudad de Toledo, una pila dorada con las armas del rey, tasada en 360 reales de vellón ${ }^{33}$. O que también podían expresar la devoción por determinada figura, como quedaba patente cuando en ellas se tallaba una imagen de la Virgen, a la que así mismo se relacionaba directamente con la pureza femenina anteriormente mencionada.

Respecto a los relicarios, eran los lugares donde se recogían y guardaban las reliquias ${ }^{34} \mathrm{y}$ por derivación del término también los adornos con los que se guarnecían aquéllas, normalmente fabricados en metal, pero también en otras materias y atendiendo a diferentes formas o "hechuras".

Algunas iglesias y monasterios reservaban un espacio específico para custodiar y exhibir las reliquias. Sin embargo, los relicarios inventariados entre los enseres domésticos, solían materializarse en pequeñas piececitas cuyos propietarios y propietarias portaban formando parte de su indumentaria. Fue corriente el uso de medallonesrelicarios, aunque no de todos los que tenemos testimonio se puede asegurar que contuvieran vestigia correspondiente a advocación alguna. Los hubo que tomaron este nombre y que dentro del marco acristalado por ambas caras que componía su estructura contenían alguna estampa. Iconografías de San José, la Virgen y el Niño, San Juan, Nuestra Señora del Carmen, San Francisco o San Antonio son algunas de las documentadas.

Estos elementos aparecían, una vez más, atribuidos de la múltiple funcionalidad que venimos asignando a los objetos religiosos que se hallaban dentro de la vivienda. Se trataba de un adorno que completaba la indumentaria personal, ofreciendo la imagen de católico de quien lo portaba, además de prestigiándolo socialmente si se encontraba realizado en algún metal precioso, pero que, a su vez, servía a su portador a modo de "talismán" o amuleto que le iba a proteger, a causa de la devoción que sentía por aquel atributo sagrado o advocación.

Al relicario como adorno personal, debemos añadir los rosarios, así como las medallas o las "crucecitas". No obstante, el escaso valor económico de la mayor parte de éstas, reiterado en las apreciaciones que se llevaron a cabo en las escrituras notariales, permite afirmar que el valor predominante que se concedía a dichas piezas por parte de quienes las poseían era el devocional. Al que en algunas ocasiones debía sumarse además el sentimental que contenían por tratarse de un regalo o un pequeño, pero cargado de valor simbólico, legado familiar.

No obstante, también se han hallado arquitecturas propiamente dichas contenedoras de reliquias como la que formaba parte del capital de bienes de Francisco Bovadilla y Alcocer:

Una reliquia de Nuestro padre San Francisco de Asís que un sumo pontífice regaló a una señora reina de España y ésta a don Diego Bovadilla, abuelo del otorgante, engastada en Roma en plata de nubes, arca y flores con acero, serafines, rayos dorados sobre

33 AHPM. Prot. 19510, f. 372 r.

34 SÁNCHEZ REYES, G.: "Retablos relicario en la Nueva España", Actas III Congreso internacional del Barroco americano: Territorio, Arte, Espacio y Sociedad, Sevilla, Universidad Pablo de Olavide, 2001, pp. 616-630 
bronce y empavonado de azul de vara escasa de alto y su caja dorada con un cristal de medio punto, estimado todo en mil y trescientos reales de vellón ${ }^{35}$.

\section{Alcobas y dormitorios}

Alcobas y dormitorios debieron constituir otros espacios dentro de la vivienda en los que dar cabida a las prácticas devocionales por parte de sus moradores. Su aparición dentro de los planos de las casas de los servidores de la Monarquía se elevaba a un $62,96 \%$ de los casos para la alcoba y un 19,13\% para el dormitorio. Por lo tanto, muchos más comunes que los oratorios; adquirían un sentido más personal, donde llevar a cabo de una forma más íntima la oración, la reflexión, aunque, sin embargo, carecían del carácter sagrado del que se dotaba a aquellos. La presencia de lo religioso se afirmaba mediante la aparición de imágenes, las cuales, como ya se haya mencionado, cobraron un fuerte poder como reflejo de la religiosidad contrarreformista post-tridentina, frente a la Iglesia Reformada, que había descartado su utilización en el marco de una piedad y unas prácticas devotas alejadas de la exteriorización del sentimiento religioso a través, entre otros usos, del culto a las imágenes ${ }^{36}$.

Las representaciones existentes en dichas estancias encontraron soportes materiales diferentes. Pinturas ${ }^{37}$, estampas ${ }^{38}$, grabados y tallas, como elementos con valor piadoso en sí mismos, se combinaron con la aparición de imágenes en un mueble de un alto valor simbólico como la cama.

El mueble aportado en su dote, fechada en el año 1780, por doña Ana María Vicente, esposa de don Pedro Antonio de Cuéllar, portero de estrados en propiedad del Consejo de la Inquisición, era descrito de la siguiente manera: "Una cama imperial con su testero dorado y encarnado en dibujo y una María en medio" "39. Ésta fue tasada en 420 reales de vellón. La cama imperial era un mueble fabricado para ser exhibido dentro de una alcoba o dormitorio de aparato de aquellos que formaban parte de las zonas de respeto de las viviendas de las elites. El dibujo de la Virgen María que aparecía en esta cama podemos entenderlo, una vez más, desde una perspectiva múltiple. En primer lugar, la devoción hacia la figura de la Virgen por parte de su propietaria. En segundo, el sentido protector de la imagen religiosa situada sobre el cabecero de la cama, como cuidadora del matrimonio que en ella se iba a consumar y de la descendencia que de él resultare. Además, se ha de tener en cuenta la alta mortalidad, así de madres como de neonatos, que se producía en los partos; por lo que, la presencia de la Virgen en el cabecero de la cama donde tenía lugar el alumbramiento no estaba de más para proteger a madres e hijos. Y, finalmente, como medio para demostrar el carácter de fieles católicos de sus propietarios.

\footnotetext{
35 AHPM. Prot. 19510/388 r.-388 v.

36 GONZÁLEZ SÁNCHEZ, op. cit. (nota 1), pp. 387-405

37 BRAVO LOZANO, J.: "Pintura y mentalidades en Madrid a finales del siglo XVIII", Anales del Instituto de Estudios Madrileños, n. XVIII (1981), pp. 193-220

38 PORTÚS, J. y VEGA, J.: La estampa religiosa en la España del Antiguo Régimen, Madrid, Fundación Universitaria Española, 1998

39 AHPM. Prot. 19007, f. 35 r.
} 
A un modelo de similares características respondía el mueble que aparecía entre los bienes del precitado subteniente de milicias de la ciudad de Toledo, don Francisco Bovadilla Alcocer, en 1788: "Una cama grande dada de azul de tablitas y pies, imperial con su cabecera tallada de realce dorada, una María de talla y una corona encima dorada y tallada en quinientos reales" ${ }^{40}$. Pero, los cabeceros de cama también podían aparecer guarnecidos de otros elementos de carácter sagrado como los anteriormente mencionados relicarios. Doña Rosalía Armona, hija del contador general de la Regalía de Aposento de Corte, don Antonio Armona, llevaba formando parte de su dote en el año 1803: "Un relicario para la cabecera de la cama bordado de lentejuelas, y flores con su cristal" 41 , tasado en sesenta reales de vellón.

Las imágenes religiosas debieron centrar así mismo la temática de las diferentes muestras de pintura, estampa, grabado y escultura que se ubicaban en alcobas y dormitorios. Obras de un formato pequeño, con respecto a las que podían encontrarse en otras piezas de la casa como la sala, que contenían una alta carga simbólica. El hecho de hallarse ubicadas en estancias destinadas al recogimiento del individuo nos permite percibir, en buena medida, las devociones de aquél. Imágenes ante las que postrarse a orar, cuyos valores artístico o económico no eran lo más importante, sino que su estimación se basaba en su carga sagrada ${ }^{42}$.

La Virgen ${ }^{43}$ concebida como intercesora entre el devoto y la divinidad adquirió un protagonismo sin precedentes entre las devociones de las mujeres, debido a su condición femenina. La Encarnación debió constituir una devoción frecuente que proporcionaba consuelo y apoyo espiritual entre las mujeres en el momento de afrontar un embarazo y el consecutivo alumbramiento. Aunque también escenas femeninas como la de la Visitación, donde se representaba a la Virgen María visitando a su parienta Isabel -encinta-, tras la Anunciación por el Ángel Gabriel ${ }^{44}$.

Ambas representaciones aparecieron entre los bienes dotales que aportó en 1795 a su matrimonio con don José Manuel de Plaza y Torrecilla, abogado de los Reales Consejos, doña María Antonia Zamora y Sauca: "Dos pinturas iguales la una de la Visitación y la otra de la Encarnación de vara y media de alto y vara y cuarta de ancho con sus marcos dorados en seiscientos reales" ". La misma imagen de la Encarnación la hallamos también entre los bienes que formaban parte de la carta de dote de doña Joaquina Aguado, esposa de don Buenaventura Manuel de la Viya, oficial tercero de la Secretaría del Ayuntamiento de Madrid para el mismo año: "Dos láminas de a cuarta, San Francisco y el Misterio de la Encarnación con cristal y marco dorado

\footnotetext{
40 AHPM. Prot. 19510/388 v.

41 AHPM. Prot. 21897/45 v. (3ª foliación)

42 CHRISTIN, O. y GAMBONI, D. (eds.): Crises de l'image religieuse, Paris, Éditions de la Maison des Sciences de l'homme, 1999

43 PORTÚS PÉREZ, J.: El culto a la Virgen en Madrid durante la Edad Moderna, Madrid, Consejería de Cultura de la Comunidad de Madrid, 2000

44 CARLOS VARONA, M. C. de: "Representar el nacimiento. Imágenes y cultura material de un espacio de sociabilidad femenino en la España Alto Moderna", Goya. Revista de Arte (2007), pp. 231-245; MUSACCHIO, J.: "Conception and birth" en AJMAR-WOLLHEIM, M. y DENNIS, F. (eds.): At home in Renaissance Italy, Londres, V\&A Publications, 2006, pp. 124-136

45 AHPM. Prot. 20385, s/f
} 
en sesenta" ${ }^{46}$. Así como constituyendo el patrimonio personal de doña Juliana Díaz Manrique, esposa del regidor del Ayuntamiento madrileño don Fernando Gómez Lozano en 1803: "Otra compañera de la antecedente de Nuestra Señora de la Encarnación con igual marco en diez reales" ${ }^{\prime 4}$. Sin embargo, el valor económico marca una diferencia entre las de precio más alto, que pudieran combinar su carácter como obras de arte con el devocional, y aquéllas concebidas únicamente para su adoración.

Las funciones de la maternidad a las que venimos refiriéndonos hallaron así mismo reflejo en la posesión de figuras del Niño Jesús ${ }^{48}$. Imágenes de la Virgen con el Niño en sus brazos o sobre su regazo, reflejo de la maternidad ideal; pero también el Niño o San Juan como esculturas individuales, comprendidas dentro de un proyecto pedagógico en el que su uso se concebía a modo de instrumentos de aprendizaje para su propietaria en las formas de cuidado y atención de los hijos. Las características de los dos Niños de talla, de tres cuartas de alto, que también formaron parte de la dote de doña María Antonia Zamora y Sauca ${ }^{49}$, bien pudieron cumplir con esta función práctica que extralimitaba las propias de una escultura de carácter religioso.

No obstante, en contraposición a la tradicional concepción de que las imágenes de la Virgen madre, acompañada del Niño Jesús, predominaron entre los bienes femeninos, frente a los masculinos; sin tener la posibilidad de penetrar en los niveles del sentimiento devocional que cada uno de los sexos pudo sentir hacia aquéllas, su presencia no se muestra tan desigual entre las elites madrileñas a finales del siglo XVIII. Se ha calculado un $56,25 \%$ de existencia de dicho motivo entre los bienes de mujeres $y$ un $43,75 \%$ entre los de los hombres.

Si la Virgen se erigió en paradigma de la maternidad, San José lo hizo en el de la paternidad. Y el conjunto de la Virgen, San José y el Niño, es decir, de la Sagrada Familia en motivo de representación en imágenes por lo general de pequeño formato y escaso valor económico, salvo casos excepcionales, como ocurría con la pintura de "San José, la Virgen y el Niño de una vara y dos dedos de alto y tres cuartas y tres dedos de ancho marco dorado éste en treinta reales y aquel en ciento cincuenta todo ciento y ochenta" ${ }^{50}$, a la que se sumaba otra donde la "Sacra Familia" se veía aumentada con la presencia de San Joaquín y Santa Ana, los padres de la Virgen: "Otro de la Virgen, Santa Ana, el Niño, San José y San Joaquín con su marco dorado de cinco cuartas de alto y una vara de ancho marco dorado este en sesenta reales y aquel en trescientos todo trescientos y sesenta reales" ${ }^{51}$. Ambas pertenecientes al capital de bienes de don Pedro Prudencio de Taranco en 1780. O también la que se inventarió

\footnotetext{
46 AHPM. Prot. 20557, f. 79 r. (2 $2^{\text {a }}$ foliación)

47 AHPM. Prot. 21982, f. 33 v.
}

48 BARIEAU MAULDIN, B.: Images of the Christ Child. Devotions and iconography in Europe and New Spain, Tesis doctoral inédita. Universidad de Nuevo México, 2001; GARCÍA SANZ, A.: "Análisis de una devoción doméstica: La imagen del Niño Jesús en diferentes ámbitos de la vida cotidiana", en FRANCO RUBIO, G. A. (ed.): La vida de cada día. Rituales, costumbres y rutinas cotidianas en la España moderna, Madrid, Almudayna, 2012, pp. 229-247; KLAPISCH-ZUBER, Ch.: "Holy dolls. Play and piety in Florence in the Quattrocento", en KLAPISCH-ZUBER, Ch.: Women, family and ritual in Renaissance Italy, Chicago, Londres, University of Chicago Press, 1985, pp. 310-329

49 AHPM. Prot. 20385, s/f

50 AHPM, Prot. 18072/207 r.

51 Ibidem. 
entre los muebles de don Domingo Martínez: "Otra pintura de la Sacra Familia en 240 reales de vellón" 52 .

\section{Espacios de recepción}

Ciertas estancias dentro de las viviendas de las elites al servicio de la Monarquía fueron concebidas para cumplir con la función específica de espacios destinados a la recepción de visitantes. En ellas primaba la exhibición de una serie de elementos capaces de mostrar la condición de su propietario.

Un mueble que cumplió fielmente con este objetivo fue el escaparate o urna religiosa. Representaba en sí mismo una pieza de carácter expositor. Su estructura se componía por una armadura realizada en metal o madera y vidrios, a través de los cuales exhibir su contenido. Este último podía ser de lo más variado, desde esculturas de bulto figurativas de Cristos, Vírgenes, Niños Jesús, Santos, a pequeñas piezas como medallas, relicarios o rosarios. El pleno desarrollo de este mueble fue alcanzado durante la segunda mitad del siglo XVII; atestiguado a través de su presencia en las viviendas ${ }^{53}$. Con la llegada de la Casa Borbón al trono español y la paulatina introducción de nuevos modelos procedentes de Francia, dicha pieza fue perdiendo importancia a lo largo del siglo XVIII y su aparición en la documentación que enumeraba los bienes que componían las viviendas disminuyendo. No obstante, no todos se perdieron y somos capaces de reconocer en ellos, así como ya lo hayamos hecho para otros objetos de carácter piadoso o devocional, un valor familiar mediante la transmisión de escaparates por vía dotal. Un mueble antiguo, que formaba parte de los bienes de la familia, y que era transmitido a través de una hija al nuevo núcleo familiar que se estaba formando mediante un matrimonio. Éste debió ser el caso de las: "Dos urnas iguales con sus cristales de tercia y dentro de ellas varias frutas imitadas de cera y un Niño Jesús de la misma especie en trescientos reales de vellón"54, aportadas a su matrimonio con el viudo don José Chavarino, en 1780, por doña Margarita Gutiérrez Duquén, hija de don Juan Francisco Gutiérrez, quien fuera capitán del Regimiento de Caballería de Brabante.

Un motivo interesante en el que reparar y que podía aparecer como escena central dentro de estas urnas era el Nacimiento. De muy escaso valor económico era el que se inventarió en 1795 entre los bienes del fallecido don Francisco Landini, primer violín de la Real Capilla, y que heredaría su yerno, don José de Zayas, en condición de esposo de la hija del finado, doña María Luisa Landini: "Una urnita de tercia de ancho con su cristal y dentro de él un Nacimiento con figuras de hueso 30"55. Éste tendría poco que ver con el que para la misma fecha se describía en la escritura de partición de los efectos de don Antonio Marcelino de Armesto: "Un nacimiento que se compone de nueve piezas de diferentes tamaños y todos de peñascos, grupos, cuevas y monterías

52 AHPM, Prot. 17644/ 376 r.

53 MORERA VILLUENDAS, A.: El escaparate, un mueble para una dinastía: Ostentación y devoción en el Madrid de los siglos Modernos, Tesis Doctoral inédita, UNED, 2010. Desde estas líneas deseo expresar mi agradecimiento a la autora por facilitarme la consulta de este trabajo.

54 AHPM. Prot. 19433, f. 595 v-596 r.

55 AHPM. Prot. 19912/99 v., 158 v. 
con el misterio de barro cocido y otras diversas figuras de lo mismo que representan hombres, mujeres y animales, un cofre en que se hallan metidas tasado todo en quinientos reales" ${ }^{56}$. Entre el primero y el segundo cabe marcarse una diferencia fundamental. Mientras al pequeño conjunto realizado en hueso de don Francisco Landini se le podía atribuir cierto valor como escena de devoción, el conjunto con el que contaba, en el cuarto bajo que habitaba en unas casas de su propiedad en la calle de Silva, don Antonio, representaba una obra escultórica, tal y como fue definida en la tasación de sus bienes. Su exhibición en alguna de las estancias de recibo de la casa tendría lugar durante la Navidad, permaneciendo el resto del año guardado dentro del precitado cofre. Durante aquellos días en los que se mantenían expuestas, dichas figuras habían de cumplir a su vez con una finalidad pedagógica. Probablemente, a través del mencionado conjunto y sirviéndose de la técnica de la teatralización de la escena sagrada se ilustró a los tres hijos del matrimonio -doña Juana, don Manuel Domingo y don José- en el misterio del Nacimiento de Cristo.

Algunas grandes casas incluso llegaron a anunciar en la prensa periódica su apertura para exhibir suntuosos Nacimientos, tal y como señalara Jesusa Vega en el caso del marqués de la Olmeda. El que ocupara diferentes cargos dentro de la Orden de Santiago, en el Consejo de Órdenes Militares, daba a conocer en diciembre de 1761 la siguiente información en el Diario Noticioso:

La persona que quisiere ver un Nacimiento muy primoroso, con todas las figuras de movimiento acuda a la casa del señor marqués de la Olmeda que está en la calle de Jacometrezo entrando por la plazuela de Santo Domingo, primera puerta de mano izquierda cuarto bajo, previniéndose que desde el día 24 en adelante lo dejarán ver a todas horas dando un real de vellón cada persona ${ }^{57}$.

Respecto a la pintura que vistió las paredes de estos espacios de recepción, los cuadros de gran formato, enmarcados en marcos dotados de valor en sí mismos por su talla y dorado, debieron adquirir algunos matices diferentes a las imágenes pictóricas que colgaban de las paredes de alcobas y dormitorios. A su valor devocional debieron precederle sus características como obras de arte, destinadas a decorar la estancia en la que se encontraban ubicadas ${ }^{58}$. Piezas tasadas por los especialistas en cifras que tendían a superar los 300 reales de vellón y de las que en ciertas ocasiones se informaba de la identidad de su autor, reflejaban la condición católica de su propietario, a la vez que su estatus socio-económico, e incluso, cuando se encontraban formando parte de amplios conjuntos, de una faceta coleccionista. La aparición de estas imágenes tampoco debemos despojarla en absoluto de su marcado carácter como ilustraciones de los gustos y modas de la sociedad de la época.

56 AHPM. Prot. 19519/885 r.-885 v.

57 Citado por VEGA GONZÁLEZ, J.: "Transformación del espacio doméstico en el Madrid del siglo XVIII: del oratorio y el estrado al gabinete", Revista de Dialectología y Tradiciones Populares, LX/2 (2005), p. 217; vid. CAUSA, R.: "El belén cortesano", en SPINOSA, N.: El arte en la corte de Nápoles en el siglo XVIII, Madrid, Ministerio de Cultura, 1990, pp. 295-298; VAREY, J. E.: Cartelera de titeres y otras diversiones populares de Madrid: 1758-1840, Londres, Támesis, 1995

58 CHRISTIN, O. y GAMBONI, D., op. cit. (nota 42) 
El culto a la Inmaculada Concepción, que Roma se vio forzada a oficializar debido a la fuerza que adquirió y su impulso en España por parte de la Monarquía, convirtieron la representación de Nuestra Señora de la Concepción en habitual ${ }^{59}$. Su presencia en los hogares madrileños de las elites vinculadas al servicio del Estado se estima en un $30 \%$, dentro del cual en el $63 \%$ de los casos dicha devoción se materializaba en bienes aportados por la futura esposa. Así, la precitada doña Margarita Gutiérrez Duquén aportaba a su matrimonio: "Una imagen de la Concepción con su marco dorado de dos varas y media de largo y una y media de ancho en seiscientos reales de vellón" ${ }^{60}$. Ésta se encontraba entre otras piezas de alto valor económico, de cuyo carácter suntuario no cabe la menor duda:

Una imagen de Nuestra Señora del Populo romana en cristal con marco dorado en cuatrocientos reales de vellón

Otra de la Soledad en cobre de más de media cuarta con su marco en seiscientos reales de vellón

Dos láminas de miñatura una de Jesús y otra de su madre Santísima con marcos de ébano y con sus cristales en seiscientos reales de vellón ${ }^{61}$.

La Inmaculada Concepción aparecía así mismo representada cobrando el sentido que se acaba de expresar entre los bienes de doña María Antonia de Quintana Recacoechea en 1795. La hija de don Antonio de la Quintana, miembro del Real Consejo de Hacienda y esposa del mariscal de campo don Diego Ventura de Mena y Cortés aportaba: "Una pintura de Nuestra Señora de la Concepción como de dos varas de alto y una y cuarta de ancho, marco dorado con tarjetas, en cuatrocientos reales" ${ }^{2}$. Al igual que lo hiciera doña Magdalena de Bretín, futura esposa del oficial cuarto de la Dirección General de Rentas, don Miguel Ignacio de Villacastín, en el mismo año 1795: "Una Concepción grande con su marco dorado en setecientos ochenta reales" ${ }^{63}$. De precio próximo lo era también la que formaba parte del aumento de dote que escrituró el ya mencionado don Fernando Gómez Lozano en 1803 a favor de su esposa doña Juliana Díaz Manrique: "Una pintura de Nuestra Señora de la Concepción de dos varas y media de alto y vara y dos tercias de ancho, marco dorado con tarjetas antiguas en setecientos y veinte reales" ${ }^{64}$, cuya manufactura contrastaba con una segunda pintura del mismo tema de una calidad infinitamente inferior, además de haber sufrido el deterioro del tiempo, cuya ubicación dentro de la vivienda desconocemos, pero intuimos que debía encontrarse en una situación alejada de la primera y por lo tanto fuera de un espacio de exhibición propiamente dicho. Se describía de la siguiente manera: "Otra de Nuestra Señora de la Concepción pintada a lo antiguo ordinaria y maltratada de dos varas de alto y lo correspondiente de ancho marco

\footnotetext{
59 STRATTON, S.: "La Inmaculada Concepción en el arte español”, Cuadernos de arte e iconografía, t. 1, n. 2 (1988), pp. 3-128

60 AHPM. Prot. 19433/595 r.

61 Ibidem

62 AHPM. Prot. 20078, f. 322 v.-323 r.

63 AHPM. Prot. 20678, f. 11 r. (7 $7^{\text {a }}$ foliación)

64 AHPM. Prot. 21982, f. 32 v.
} 
negro en veinte y cuatro reales" ${ }^{\prime 65}$. La culminación de la imagen de la Inmaculada Concepción como obra artística concebida para ser exhibida en uno de los principales espacios de representación dentro de la vivienda fue la aportada en 1803 por doña María de la Concepción Martínez de Viergol, futura esposa de don Pedro Monfort y Viergol, abogado de los Reales Consejos y contador de los Propios, Sisas y Rentas de Madrid, dentro de su dote: "Un cuadro grande de Nuestra Señora de la Concepción con marco dorado, su autor Castro, en dos mil reales"

Condición similar, como obra artística, debió de concedérsele a otras representaciones de la Virgen en diferentes advocaciones. Así, la pintura de la Asunción de la Virgen María aportada como bien dotal de doña Inés María de Mateo, hija de don Bartolomé Mateo y García, oficial de contralor de la Real Casa, Capilla y Cámara de su majestad y esposa de don Juan de la Cruz Adanero, tesorero del Monte Pío para viudas de alcaldes mayores y corregidores del reino: "Una pintura de Nuestra Señora de la Asunción, original de Matías de Torres de dos varas y media de alto y dos escasas de ancho con marco dorado tasada últimamente en mil y quinientos reales"67. Magníficas obras donde la explícita mención de los artistas a los que se les atribuían dejaba patente su importancia como bien material.

\section{EPÍLOGO}

Desde estas páginas se ha pretendido presentar una serie de resultados relativos al terreno de la religiosidad dentro del grupo socio-profesional que constituían los servidores de la Monarquía en la capital a finales del siglo XVIII. El análisis se ha contextualizado en el marco cotidiano que proporcionaba la casa para la realización de buena parte de las prácticas relacionadas con la devoción por parte del individuo. De ahí que se haya considerado lo apropiado de estudiar su configuración arquitectónica - los distintos espacios - y los objetos o elementos materiales de carácter religioso o propios de la liturgia que los componían. La reflexión, a partir del cruce de las variables: individuo/familia, sexo, estancias de la vivienda y relación de propiedad con los bienes; nos ha permitido establecer una serie de planteamientos con respecto a las prácticas desarrolladas por parte de los sujetos motivo de este análisis, e incluso a proponer varias respuestas a la cuestión acerca de qué propiciaba determinadas actuaciones.

No obstante, se trata de un tema sobre el cual continuar investigando y reflexionando, abierto a futuros análisis teniendo en cuenta otros objetos, otras advocaciones, pero también otros espacios tanto dentro como fuera de las casas.

\footnotetext{
65 AHPM. Prot. 21982, f. 33 r.

66 AHPM. Prot. 21596, f. s/f

67 AHPM. Prot. 19655, f. 14 r. (4a foliación)
} 